\title{
BMJ Open Systematic review of academic bullying in medical settings: dynamics and consequences
}

\author{
Tauben Averbuch (DD , ${ }^{1}$ Yousif Eliya, ${ }^{2}$ Harriette Gillian Christine Van Spall ${ }^{1,2,3}$
}

To cite: Averbuch T, Eliya Y, Van Spall HGC. Systematic review of academic bullying in medical settings: dynamics and consequences. BMJ Open 2021;11:e043256. doi:10.1136/ bmjopen-2020-043256

- Prepublication history and additional supplemental material for this paper are available online. To view these files, please visit the journal online (http://dx.doi.org/10.1136/ bmjopen-2020-043256)

Received 29 July 2020 Accepted 04 May 2021
Check for updates

(C) Author(s) (or their employer(s)) 2021. Re-use permitted under CC BY-NC. No commercial re-use. See rights and permissions. Published by BMJ.

${ }^{1}$ Medicine, McMaster University, Hamilton, Ontario, Canada

${ }^{2}$ Health Research Methods, Evidence and Impact, McMaster University, Hamilton, Ontario, Canada

${ }^{3}$ Cardiology, Population Health Research Institute, Hamilton, Ontario, Canada

Correspondence to Dr Harriette Gillian Christine Van Spall;

Harriette.VanSpall@phri.ca

\section{ABSTRACT}

Purpose To characterise the dynamics and consequences of bullying in academic medical settings, report factors that promote academic bullying and describe potential interventions.

\section{Design Systematic review.}

Data sources We searched EMBASE and PsycINFO for articles published between 1 January 1999 and 7 February 2021.

Study selection We included studies conducted in academic medical settings in which victims were consultants or trainees. Studies had to describe bullying behaviours; the perpetrators or victims; barriers or facilitators; impact or interventions. Data were assessed independently by two reviewers.

Results We included 68 studies representing 82349 respondents. Studies described academic bullying as the abuse of authority that impeded the education or career of the victim through punishing behaviours that included overwork, destabilisation and isolation in academic settings. Among 35779 individuals who responded about bullying patterns in 28 studies, the most commonly described (38.2\% respondents) was overwork. Among 24894 individuals in 33 studies who reported the impact, the most common was psychological distress (39.1\% respondents). Consultants were the most common bullies identified (53.6\% of 15868 respondents in 31 studies). Among demographic groups, men were identified as the most common perpetrators $(67.2 \%$ of 4722 respondents in 5 studies) and women the most common victims ( $56.2 \%$ of 15246 respondents in 27 studies). Only a minority of victims (28.9\% of 9410 victims in 25 studies) reported the bullying, and most $(57.5 \%)$ did not perceive a positive outcome. Facilitators of bullying included lack of enforcement of institutional policies (reported in 13 studies), hierarchical power structures (7 studies) and normalisation of bullying (10 studies). Studies testing the effectiveness of anti-bullying interventions had a high risk of bias.

Conclusions Academic bullying commonly involved overwork, had a negative impact on well-being and was not typically reported. Perpetrators were most commonly consultants and men across career stages, and victims were commonly women. Methodologically robust trials of anti-bullying interventions are needed.

Limitations Most studies (40 of 68) had at least a moderate risk of bias. All interventions were tested in uncontrolled before-after studies.

\section{Strengths and limitations of this study}

This systematic review is comprehensive, including 68 studies with 82349 consultants and trainees, across several countries and including all levels of training.

- We defined inclusion criteria a priori and used established tools to assess the risk of bias of included studies.

- The included studies varied in their definitions of bullying, sampling bias was noted among the surveys and intervention studies were suboptimally designed.

\section{BACKGROUND}

Bullying behaviours have been described as repeated attempts to discredit, destabilise or instil fear in an intended target. ${ }^{1}$ Bullying can take many forms from overt abuse to subtle acts that erode the confidence, reputation and progress of the victim. ${ }^{2}$ Bullying is common in medicine, likely impacting mental health, professional interactions and career advancement. ${ }^{3-6}$ It may also impact a physician's ability to care for patients. ${ }^{7}$ Surveys from the National Health Service (NHS) in the UK showed that $55 \%$ of staff experienced at least one type of bullying; $31 \%$ were doctors in training. ${ }^{8}$ Bullying is closely related to harassment and discrimination, in which mistreatment is based on personal characteristics or demographics such as sex, gender or race. ${ }^{9}$ Within academic settings, victims may experience all three and the distinction may be less clear. Unlike harassment and discrimination, which have specific legal definitions, bullying is an amorphous term and victims are often left without legal recourse.

The hierarchical structure of academic medicine-in which there are power imbalances, subjective criteria for recruitment and career advancement, and siloed departments with few checks in place for toxic behaviours-may offer an operational environment in which bullying may be more widespread than in nonacademic medical settings. Academic bullying 
is a seldom-used term within the literature, but is intended to describe the forms of bullying that may exist in academic settings. Academic bullying can be defined as mistreatment in academic institutions with the intention or effect of disrupting the academic or career progress of the victim..$^{10}$ The prevalence of academic bullying in medical settings is unknown likely due to a lack of definition of bullying behaviours, a fear of reporting and insufficient research. There is not much known about the characteristics of perpetrators and victims, and about the impact of bullying on academic productivity, career growth and patient care. Furthermore, institutional barriers and facilitators of bullying behaviour have not been reported, and the effectiveness of interventions in addressing academic bullying has not been evaluated.

The purpose of this systematic review is to define and classify patterns of academic bullying in medical settings; assess the characteristics of perpetrators and victims; describe the impact of bullying on victims; review institutional barriers and facilitators of bullying; and identify possible solutions.

\section{METHODS}

\section{Data sources and searches}

This study followed Preferred Reporting Items for Systematic Reviews and Meta-Analyses reporting guidelines.
Two reviewers (TA, YE) searched two online databases (EMBASE and PsycINFO) for English-language articles published between 1 January 1999 and 7 February 2021, and relevant to academic bullying in medicine. An outline of the search is provided in figure 1. A combination of medical subject heading, title, and abstract text terms encompassing 'Medicine'; 'Bullying' and 'Academia' were used for the full search. The terms of the search are included in online supplemental figure S1. Two authors (TA, YE) independently screened articles for inclusion. Differences were resolved by discussion, and if necessary, by a third author (HGCVS).

\section{Study selection}

We included studies conducted in academic medical settings in which victims were either consultants or trainees. We defined academic medical settings as hospitals or clinics that were either university affiliated or involved trainees. In the case of preclinical medical students, academic medical settings included the university where medical instruction took place. Studies were included if they described: the method and impact of bullying; the characteristics of perpetrators and victims; or interventions used to address the bullying. Studies that included trainees or consultants in both academic

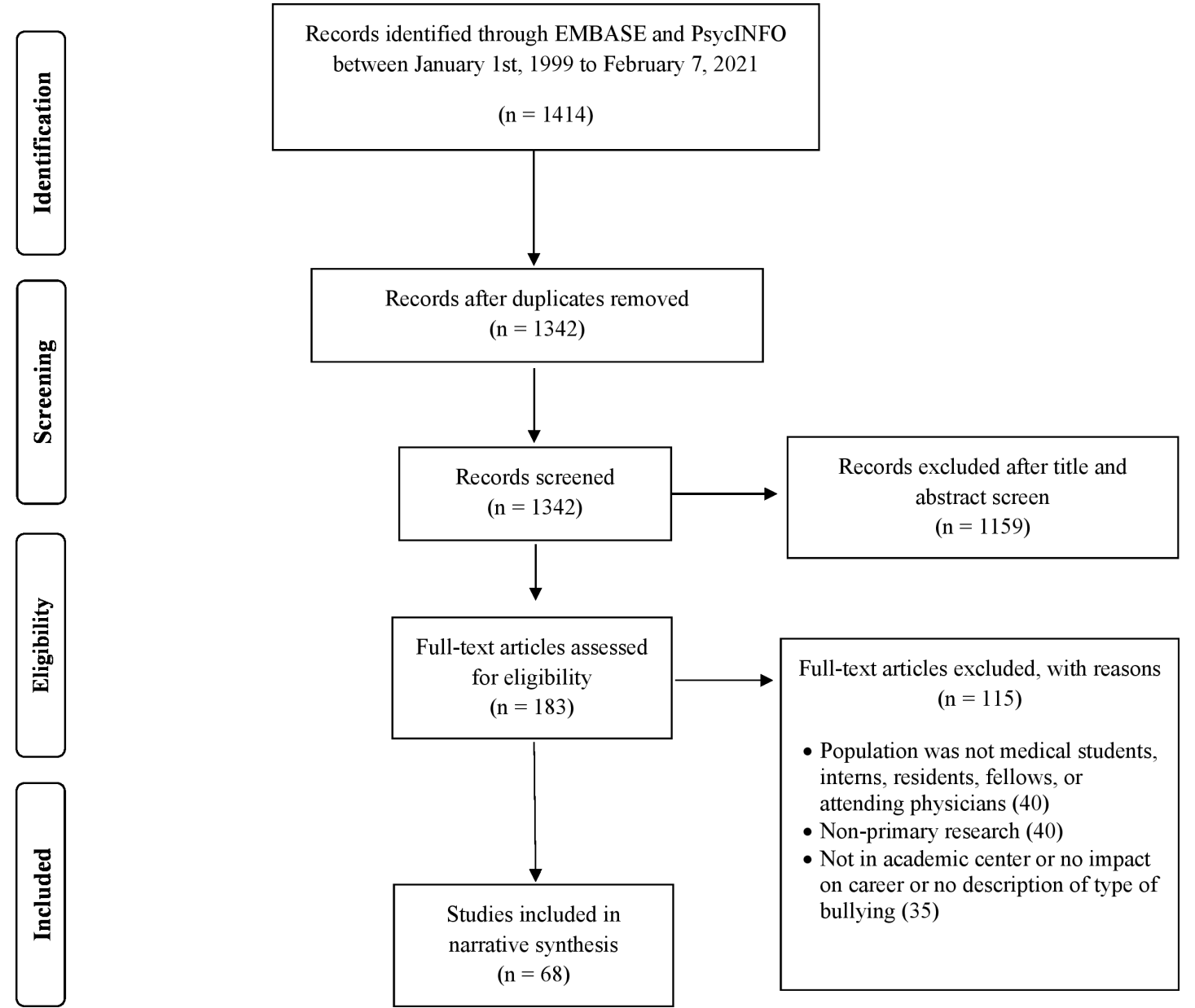

Figure 1 PRISMA diagram of included studies. We identified 68 articles relevant to academic bullying. PRISMA, Preferred Reporting Items for Systematic Reviews and Meta-Analyses. 
and non-academic settings were included. We excluded editorials, opinion pieces, reviews, conference abstracts, theses, dissertations and grey literature.

\section{Data extraction and quality assessment}

Two reviewers (TA, YE) independently extracted data on: study design, setting (academic or non-academic), definition, description and impact of academic bullying, characteristics of perpetrators and victims, barriers and facilitators of bullying, and interventions and their outcomes. Two reviewers independently assessed studies for risk of bias. We assessed before-after studies using the National Heart, Lung, and Blood Institute quality assessment tool ${ }^{11}$ and assessed prevalence surveys using the Joanna Briggs Institute critical appraisal tool. ${ }^{12}$ We classified survey studies as low risk of bias if at least 8 of 9 criteria were met, medium risk of bias if 7 of 9 were met, and high risk of bias if less than 7 were met. We classified bias in before-after studies as low if at least 11 of 12 criteria were met, medium if at least 9 of 12 were met, and high if less than 9 were met.

\section{Data synthesis and analysis}

We developed a definition for academic bullying through narrative synthesis of the definitions provided by studies included in this systematic review. We pooled the results of surveys on the basis of similarity of survey themes to facilitate a descriptive analysis. For survey studies on the prevalence or impact of bullying, we solely pooled the results of studies that asked respondents about specific bullying behaviours or impacts, respectively. We then separated results by gender and level of training. We classified groups ensuring consensus between authors. We presented our results as numbers and percentages. We calculated the denominators from the total number of individuals who completed surveys on types of bullying behaviours, the impact of bullying, characteristics of bullies and victims, or barriers to addressing academic bullying. The numerators were calculated from the number of individuals who experienced a specific behaviour or impact, were bullied by a perpetrator at a specified level of training or endorsed a specific reason for not making a formal report. We also reported the number of studies that described each specific bullying behaviour or impact, demographic characteristics of victims and perpetrators, barriers and facilitators of academic bullying, and specific reasons for not making a formal report. We could not perform a meta-analysis due to the conceptual heterogeneity between studies.

\section{Patient and public involvement}

Patients or the public were not involved in the design, conduct, reporting or dissemination plans of our research.

\section{RESULTS}

\section{Screening results}

We identified 1342 unique articles, 68 of which met inclusion criteria. Reasons for exclusion are described in figure 1.

\section{Characteristics of included studies}

Studies were most frequently set in the USA (reported in 31 studies) ${ }^{3}{ }^{13-41}$ and the UK (reported in 5 studies) ${ }^{8}{ }^{42-45}$ and were set in academic hospi-

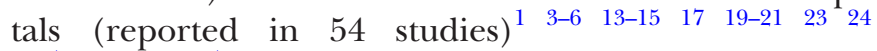
26272930 32-35 37-39 41-65 at both teaching and non-teaching sites (reported in 14 studies). ${ }^{8} 162528364066-73$ Twenty-five studies included medical students, ${ }^{3-5} 131521222426$ 33-35 373948505257-606364747507includedresidentsorfellows ${ }^{11416-182022232527-32}$ 444549-5155566162656972 and25included consultants ${ }^{6816192025283638}$ 40-43 464753 66-73 75 (table 1).

\section{Definition of academic bullying}

Six papers provided definitions for academic bullying. 4850565863 Common behaviours included abusing and punishing the victim through overwork, isolation, blocked career advancement and threats to academic standing. Thus, we defined academic bullying as the abuse of authority by a perpetrator who targets the victim in an academic setting through punishing behaviours that include overwork, destabilisation, and isolation in order to impede the education or career of the target. Multiple studies used the complete or partial Negative Acts Questionnaire, a standardised list of bullying

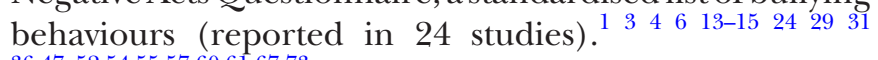
$3647-5254555760616773$

\section{Patterns of academic bullying behaviours}

There were 35779 consultant and trainee respondents to surveys of bullying behaviours (reported in 28 studies), but not all were offered the same options to select from (table 2). Bullying behaviours were grouped into destabilisation (reported in 15 studies), threats to professional status (reported in 23 studies), overwork (reported in 7 studies) and isolation (reported in 17 studies). Undue pressure to produce work was commonly reported $(38.2 \%$ of respondents affected, reported in 7 studies). ${ }^{14364547495467}$ Of the 15 studies that described destabilisation, common methods included being ordered to work below one's competency level $(36.1 \%$, reported in 10 studies) $31364547-4952677172$ and withholding information that affects performance $(30.7 \%$; reported in 9 studies). ${ }^{1429} 313647-495467$ Of the 23 studies that described threats to professional status, common methods were excessive monitoring (28.8\%; reported in 6 studies) ${ }^{14} 3647495467$ and criticism (26.9\%; reported in 12 studies). ${ }^{142129364547}$ 495254677172 Of the 17 studies that described isolation, the most common method was social and professional exclusion (29.1\%; reported in 17 studies). ${ }^{414212429313640}$ 47-4952546367 7072

There were 6179 consultant and trainee respondents to surveys that separated the prevalence of bullying behaviours by gender (reported in 11 studies). A greater proportion of women experienced all bullying

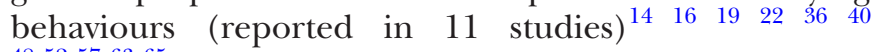
4852576365 (table 2). There were 34175 respondents to surveys that analysed results by level of training (reported 


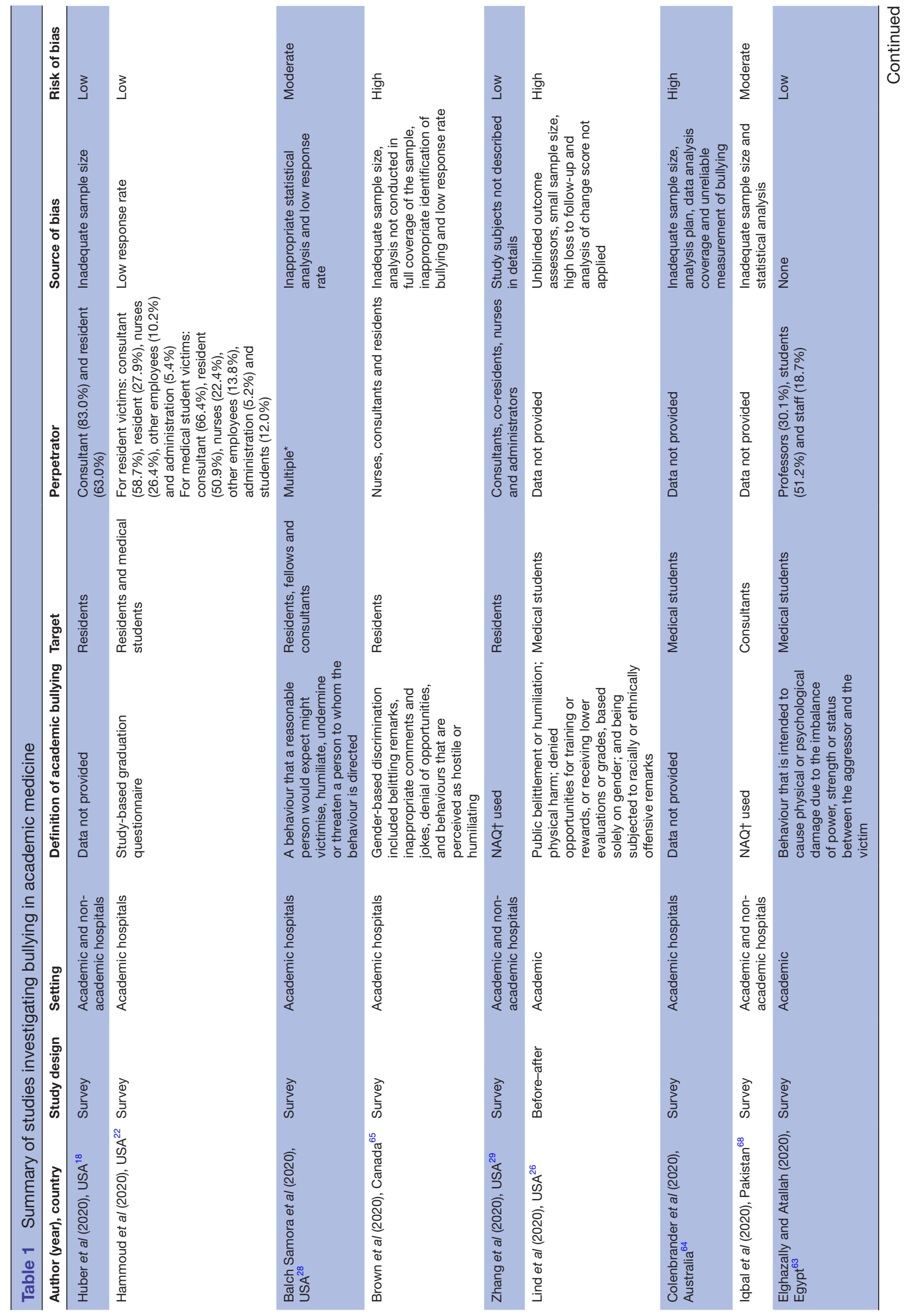

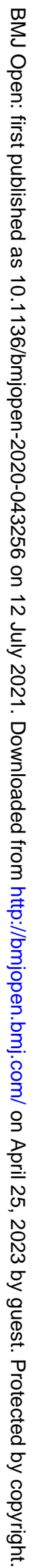




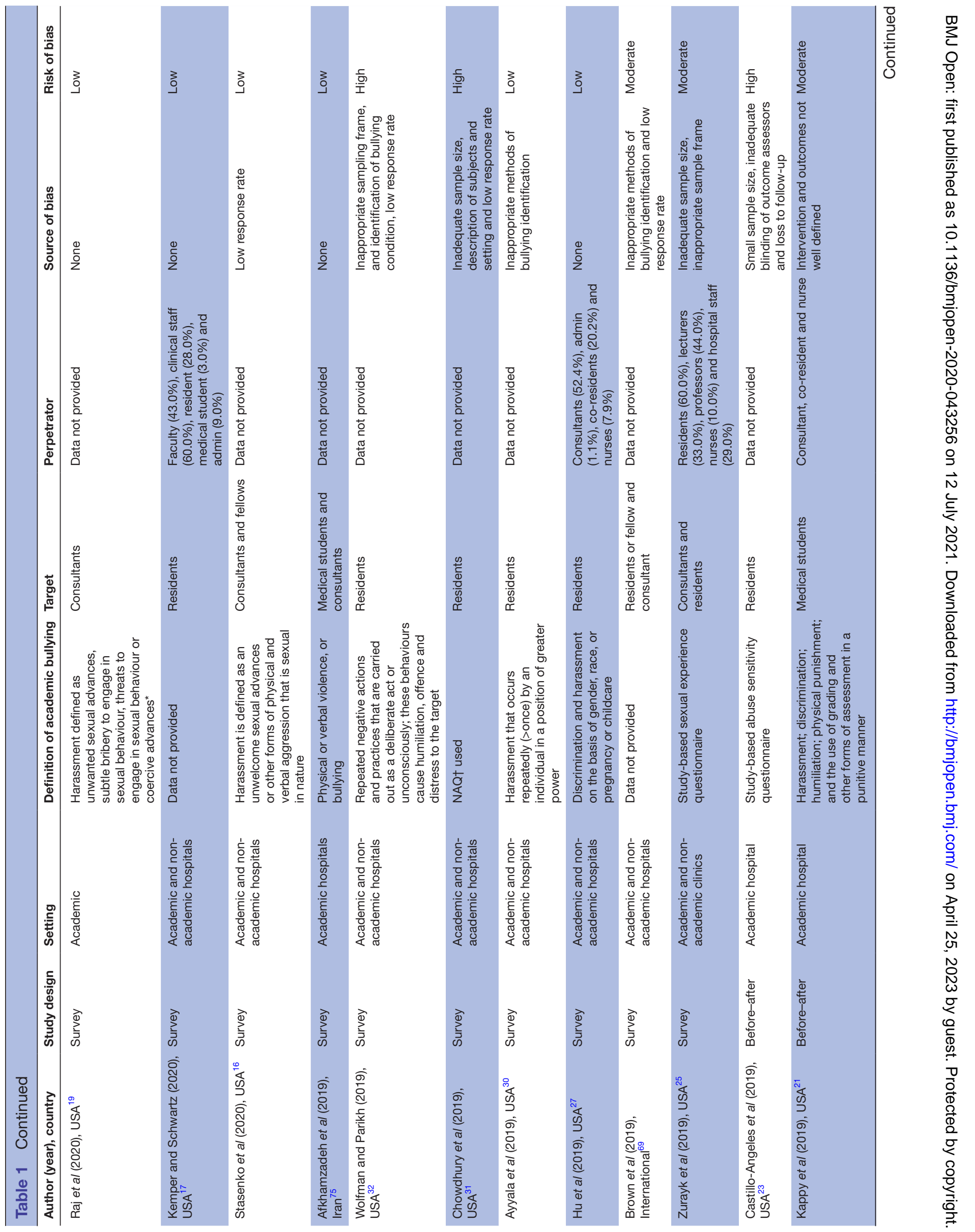




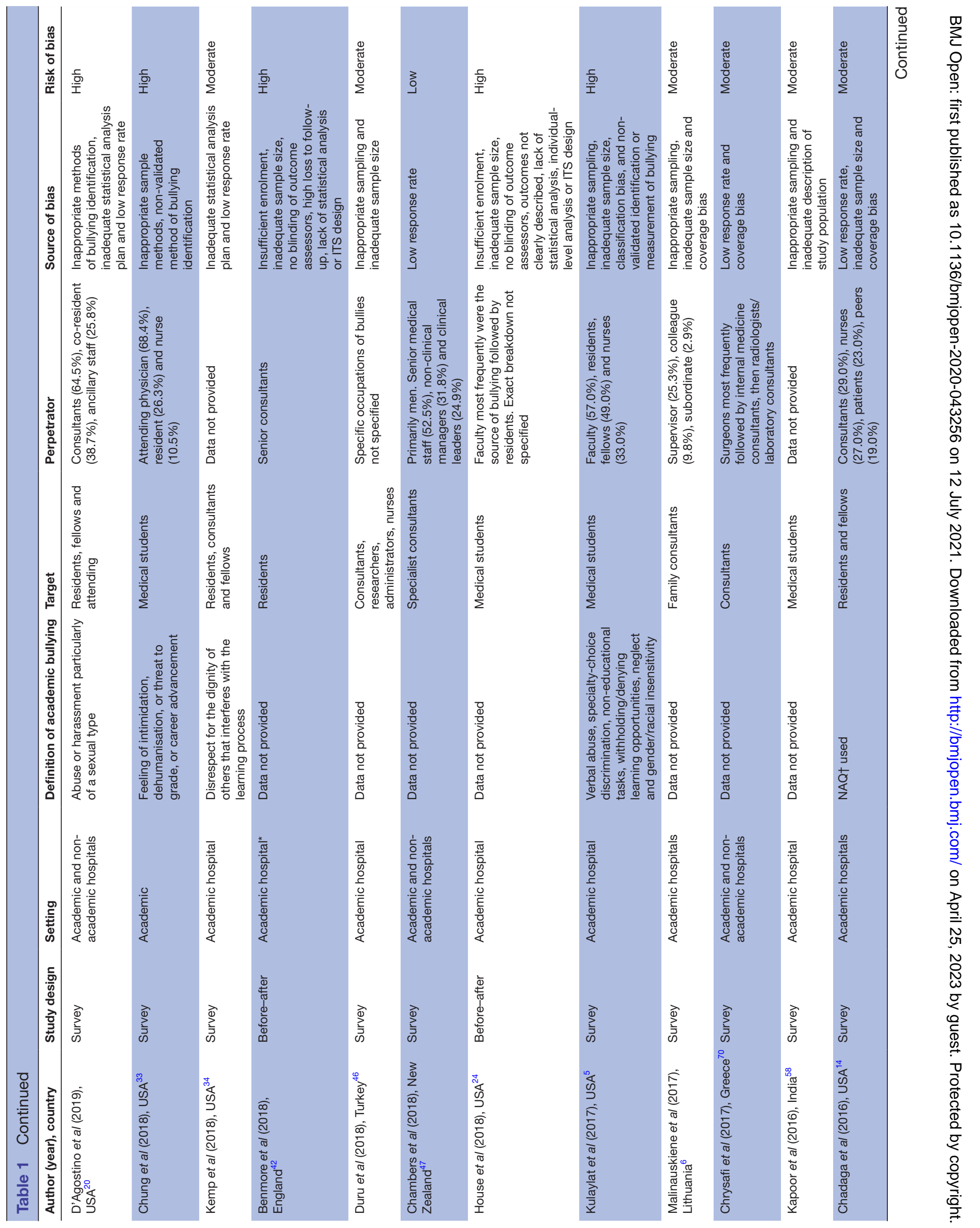




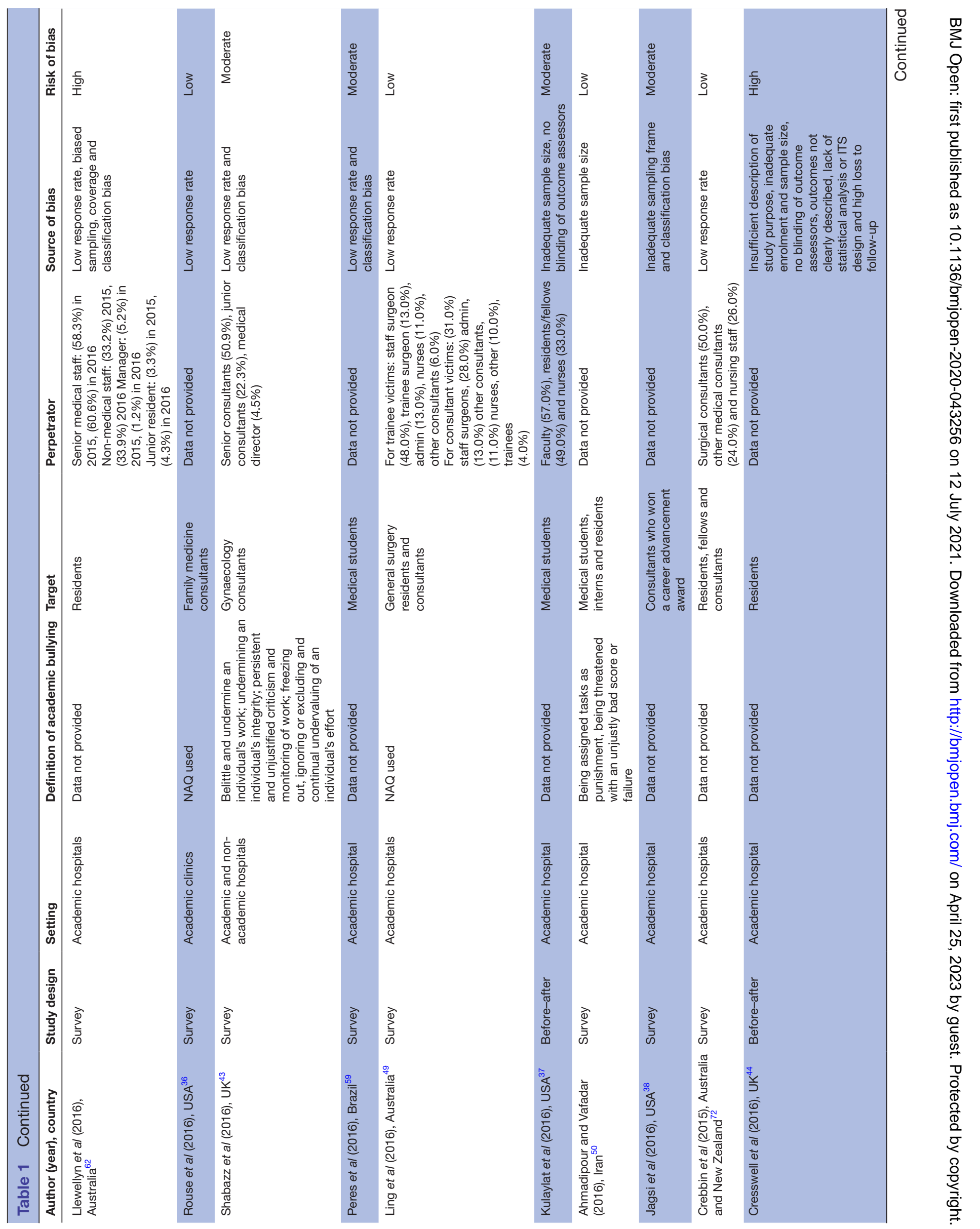




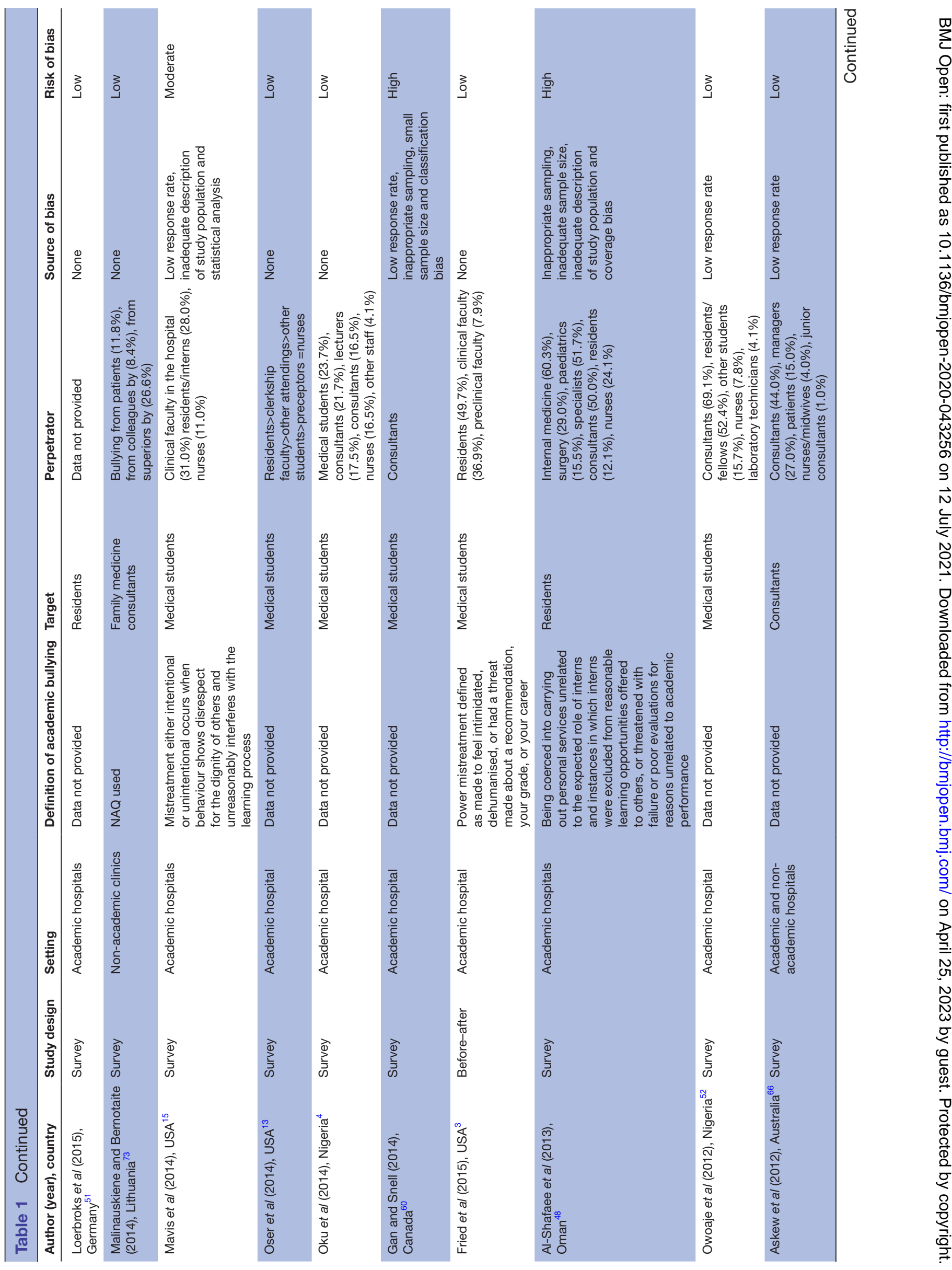

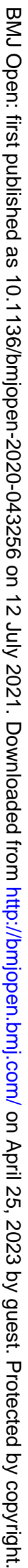




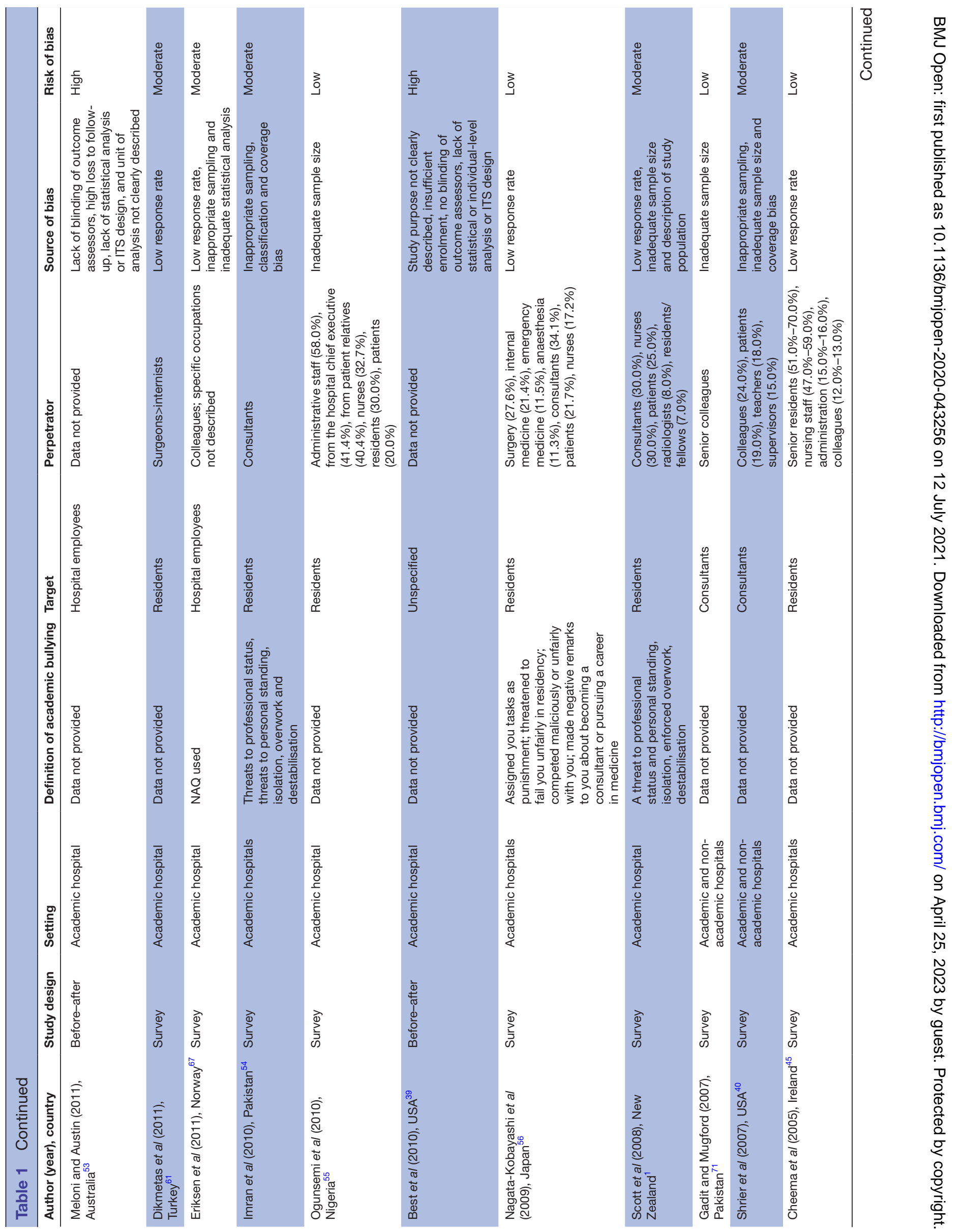




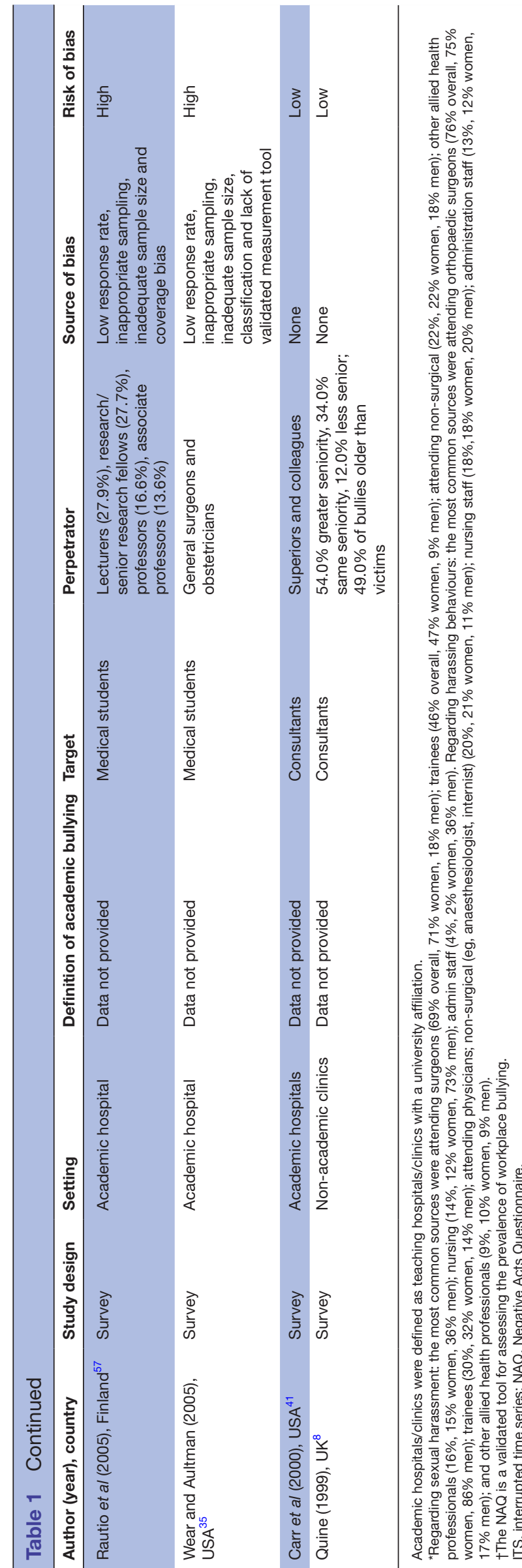

in 24 studies) (online supplemental table S1). A greater proportion of consultants experienced refusal of applications for leave, training or promotion $(26.3 \%$, reported in 3 studies), ${ }^{193647}$ and removal of areas of responsibility $(27.8 \% \text {, reported in } 2 \text { studies })^{3647}$ than residents $(11.0 \%$, reported in 3 studies; $10.7 \%$, reported in 3 studies, respectively) ${ }^{14225455}$ or medical students (13.4\%; $19.6 \%$, reported in 1 study) ${ }^{22}{ }^{24}$ Compared with medical students $\left(4.6 \%\right.$, reported in 6 studies) ${ }^{131522245257}$ and consultants (3.4\%, reported in 2 studies), ${ }^{36} 71$ a greater proportion of residents experienced the intimidatory use of discipline procedures (17.8\%, reported in 6 studies). ${ }^{142248545565}$ A greater proportion of medical students experienced persistent criticism $(66.4 \% \text {, reported in } 2 \text { studies })^{21} 52$ than residents $(28.3 \% \text {, reported in } 5 \text { studies })^{1429} 455472$ and consultants (20.8\%, reported in 3 studies). ${ }^{36} 4771$

\section{Characteristics of bullies}

Thirty-one unique studies representing 15868 consultants and trainees described the characteristics of bullies, although not all were offered the same options to select from. Common perpetrators included consultants (53.6\%, reported in 30 studies), ${ }^{1} 346814151718202227$

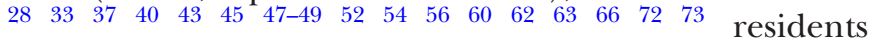
$(22.0 \% \text {, reported in } 22 \text { studies) })^{1} \begin{array}{llllllllll}3 & 6 & 8 & 15 & 17 & 18 & 20 & 22\end{array}$

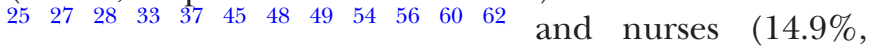
reported in 21 studies). ${ }_{1} \begin{array}{lllllllll}3 & 4 & 14 & 15 & 17 & 20 & 22 & 25\end{array}$ $272833 \quad 374548495456606273$ Of the 4277 individuals who identified the gender of their bullies, most reported primarily men $(67.2 \%$, reported in 5 studies), ${ }^{8} 36434772$ followed by primarily women $(26.1 \%$, reported in 5 studies), ${ }^{836434772}$ and both (6.7\%, reported in 3 studies). ${ }^{8} 437$ Among 6084 medical students, perpetrators were commonly consultants $(43.1 \%$, reported in 8 studies), ${ }^{3} 4152233375260$ residents $(35.7 \%$, reported in 6 studies), ${ }^{3} 1522333760$ nurses (12.4\%, reported in 7 studies $)^{341522333760}$ andothermedicalstudents $(8.8 \%$,reportedin 5 studies). ${ }^{34225263}$ Among 6289 residents, perpetrators were commonlyconsultants(52.2\%, reportedin12studies), ${ }_{11417182227}$ 454849545662 nurses $(24.3 \% \text {, reported in } 11 \text { studies })^{11417222745}$

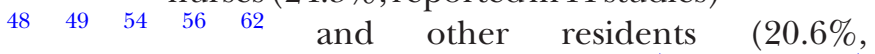
$\begin{array}{llllllll}\text { reported in } 12 & \text { studies). }{ }^{1} & 14 & 17 & 18 & 22 & 27\end{array}$ 454849545662 Of the 1500 consultants, perpetrators were their peers (39.2\%, reported in 7 studies), 684047496673 senior consultants (23.7\%, reported in 5 studies) ${ }^{68404373}$ and administration (17.7\%, reported in 4 studies). ${ }^{43474966}$

Six unique studies representing 1698 interns and medical students described the prevalence of academic bullying according to the specialty rotation of the learner. Academic bullying was common in surgery $(32.9 \%$ of respondents, reported in 6 studies), ${ }^{133448566072}$ obstetrics and gynaecology (25.5\%, reported in 2 studies $)^{1360}$ and internal medicine (21.4\%, reported in 5 studies) ${ }^{1}{ }^{1348566072}$

\section{Characteristics of victims}

Forty-one unique studies described the characteristics of victims, and 29 included the proportion of those who experienced bullying. Of the 15704 women and 19495 
Table 2 Self-reported description of specific bullying behaviours

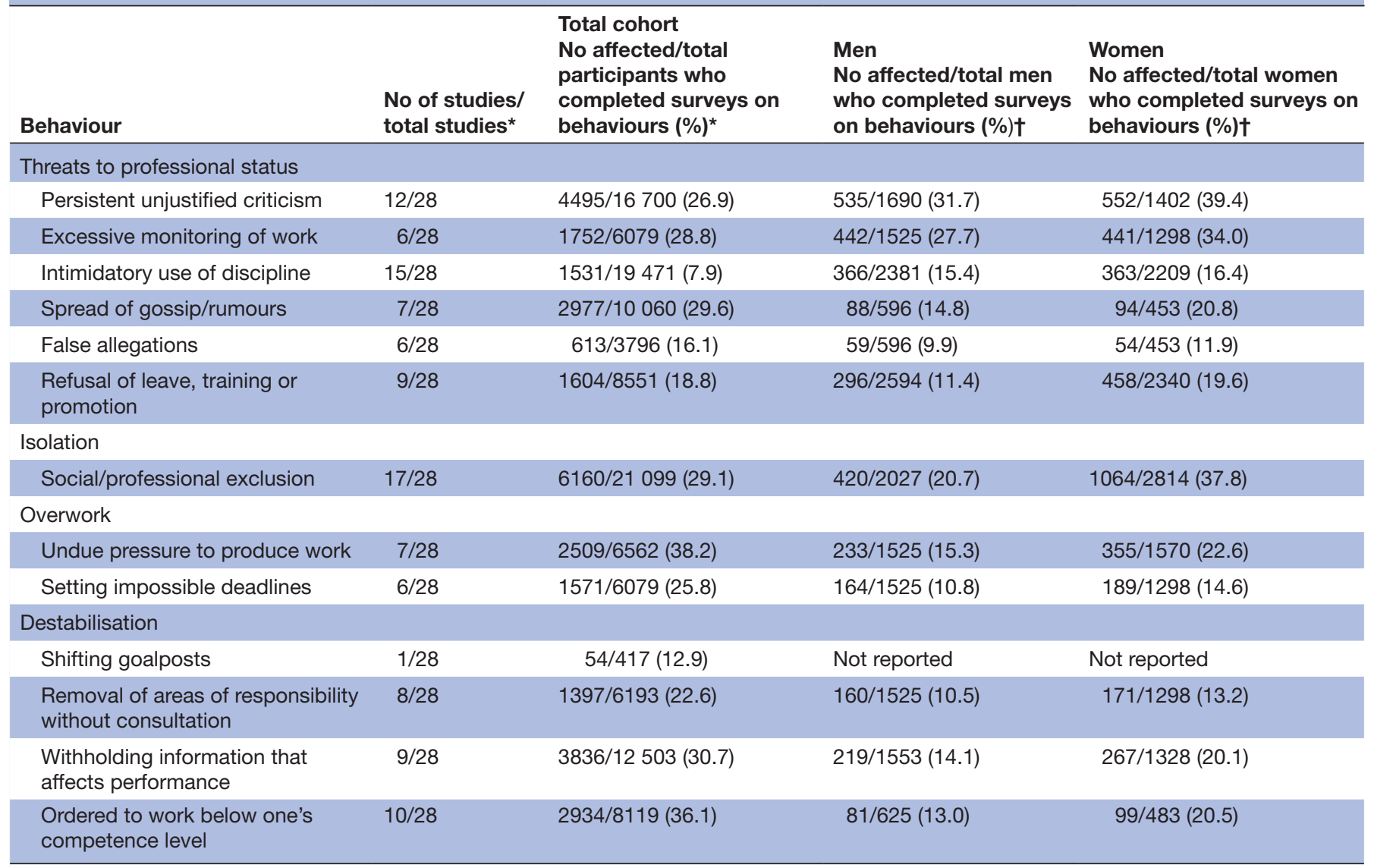

*Total number of studies that described types of bullying behaviours, including studies that did not stratify results by sex. As a result, the denominator for the number of participants in total is not the sum of the denominators for men and women. The denominator was calculated from the total number of individuals who completed surveys on specific bullying behaviours, while the numerator was calculated from the number of individuals who indicated they experienced the specified bullying behaviour. Not all survey studies offered respondents the same options to respond to, and as a result the denominators for each bullying behaviour differ.

†Of the studies that separated data by gender or solely included the results of one gender and included the specified bullying behaviour.

men who responded to surveys that analysed results by gender, women were more likely to report being bullied than men $(54.6 \%$ of all women compared with $34.2 \%$ of all men, reported in 27 studies). ${ }^{3} 414161719202728$ 363841 47-5255-57626365 697275 There were 10730 consultant and trainee respondents to surveys that separated the results by demographic characteristics other than gender, but not all characteristics were captured by each study. A greater proportion of international graduates/non-citizens experienced bullying than citizens ( $48.0 \%$ compared with $43.3 \%$, reported in 4 studies), ${ }^{14} 174572$ and a greater proportion of overweight participants (body mass index (BMI) >25) experienced bullying than those with a BMI $\leq 25(17.8 \%$ compared with $11.8 \%$, reported in 1 study).$^{51}$ The relationship between age and bullying varied based on the cut-off used and the survey sample in each study. Among consultants, a greater proportion of those with full professorship experienced bullying than assistant professors $(68.0 \%$ compared with $51.9 \%$, reported in study). ${ }^{41}$

\section{Impact of academic bullying}

There were 24894 consultant and trainee respondents to surveys on the psychological (reported in 20 studies) and career impact (reported in 25 studies) of academic bullying (table 3), although not all were offered the same options to select from. Respondents commonly reported psychiatric distress (39.2\%; reported in 14 studies), 6171827293043 47525659627173 considerations of quitting (35.9\%; reported in 7 studies) ${ }^{25314347667072}$ and reduced clinical ability (34.6\%; reported in 8 studies). ${ }^{25} 30314547525659$ Respondents agreed that academic bullying negatively affected patient safety (68.0\%; reported in 2 studies). ${ }^{18} 31$ Nine studies representing 13418 individuals described the impact of bullying according to gender (table 3). A greater proportion of women experienced loss of career opportunities (43.6\%, reported in 8 studies), ${ }^{16} 19363840415265$ while a greater proportion of men experienced decreased confidence $(32.1 \% \text {, reported in } 2 \text { studies })^{4152}$ and clinical ability $\left(26.1 \%\right.$, reported in 1 study). ${ }^{52}$

There were 16523 consultant and trainee respondents to surveys that separated results by level of training (online supplemental table S2). A greater proportion of medical students experienced psychiatric distress $(72.9 \%$; reported in 2 studies $)^{5259}$ than residents $(40.8 \%$; reported in 6 studies) ${ }^{171829305662}$ and consultants (17.9\%; reported 
Table 3 Self-reported impact of academic bullying

\begin{tabular}{|c|c|c|c|c|}
\hline Effect of academic bullying & $\begin{array}{l}\text { No of studies/ } \\
\text { total studies* }\end{array}$ & $\begin{array}{l}\text { Total cohort } \\
\text { No of affected } \\
\text { participants/total } \\
\text { participants who } \\
\text { completed surveys } \\
\text { on the impact of } \\
\text { bullying }(\%)^{\star}\end{array}$ & $\begin{array}{l}\text { Men } \\
\text { No of affected } \\
\text { men/total men who } \\
\text { completed surveys } \\
\text { on the impact of } \\
\text { bullying }(\%) \dagger\end{array}$ & $\begin{array}{l}\text { Women } \\
\text { No of affected } \\
\text { women/total } \\
\text { women who } \\
\text { completed surveys } \\
\text { on the impact of } \\
\text { bullying }(\%) \dagger\end{array}$ \\
\hline Reduced confidence in clinical skill & $8 / 33$ & $564 / 2112(26.7)$ & $68 / 212(32.1)$ & $97 / 597$ (16.2) \\
\hline \multicolumn{5}{|l|}{ Career } \\
\hline Missed career opportunities & $17 / 33$ & 2823/9442 (29.9) & $357 / 1898(18.8)$ & $1104 / 2530(43.6)$ \\
\hline $\begin{array}{l}\text { Self-reported worsening of clinical } \\
\text { performance }\end{array}$ & $8 / 33$ & $1673 / 4841(34.6)$ & $42 / 161(26.1)$ & 22/101 (21.8) \\
\hline
\end{tabular}

*Total number of studies that described the impact of bullying, including studies that did not stratify results by gender. Not all participants were given the same options to select from.

†Of the studies that separated data by gender or solely included the results of one gender and included the impact of bullying.

PTSD, post-traumatic stress disorder.

in 4 studies). ${ }^{43} 477173$ A greater proportion of residents endorsed loss of career opportunities $(35.0 \%$; reported in 3 studies) ${ }^{556572}$ compared with medical students $(16.0 \%$; reported in 3 studies) ${ }^{131552}$ and consultants (30.6\%; reported in 8 studies). 1936384041477071

\section{Barriers and facilitators of academic bullying}

Thirty-five unique studies pertained to barriers to victims making a formal report (reported in 26 studies) and institutional facilitators (reported in 25 studies) of academic bullying (table 4). There were
9239 consultant and trainee respondents to surveys on their actions taken in response to bullying and reasons for not making a formal report, although not all were given the same options to select from. Victims commonly did not formally report the bullying 13415364347 $\begin{array}{lllllllll}49 & 50 & 54 & 56 & 60 & 62 & 66 & 72 & \text {; only } 28.9 \%\end{array}$ of respondents made a formal report. Deterrents to reporting included concern regarding career implications (41.1\%; reported in 15 studies), $\begin{array}{llllll}4 & 15 & 25 & 28 & 35 & 47\end{array}$

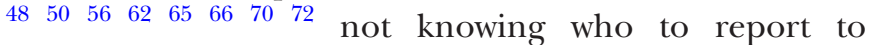

Table 4 Barriers to addressing academic bullying

Barrier

Low reporting rates

\begin{tabular}{|c|c|c|}
\hline Lack of awareness of what constitutes bullying & $5 / 35$ & $73 / 642(11.4)$ \\
\hline Lack of awareness of reporting process & $15 / 35$ & $1115 / 4215(26.5)$ \\
\hline Lack of perceived benefit & $9 / 35$ & $667 / 1621(41.1)$ \\
\hline Fear that bullying would worsen & $13 / 35$ & 969/2696 (35.9) \\
\hline Fear of career ramifications & $15 / 35$ & $1094 / 2664(41.1)$ \\
\hline Concerns regarding confidentiality & $4 / 35$ & $56 / 445(12.6)$ \\
\hline \multicolumn{3}{|l|}{ nstitutional factors } \\
\hline Hierarchical nature of medicine & $7 / 35$ & Not reported \\
\hline Recurring cycle of abuse & $3 / 35$ & Not reported \\
\hline Normalisation of bullying & $10 / 35$ & Not reported \\
\hline Lack of enforcement & $13 / 35$ & $586 / 1400(41.9)$ \\
\hline
\end{tabular}

*Total number of studies that described barriers of bullying behaviours. 


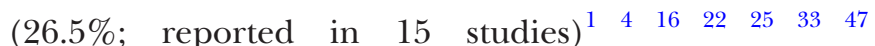
4850566265667075 and poor recognition of bullying (11.4\%; reported in 5 studies). 51525333537424856 Of the 26 studies, 7 studies representing 1139 individuals reported the outcomes of reporting ${ }^{1364347496572}$ although only a small range of outcomes were offered among options. Submitting a formal report often had no perceived effect on bullying (35.6\%; reported in 5 studies) 364347972 ; a greater proportion of victims endorsed worsening $(21.9 \%$; reported in 3) 364965 than improvement (13.7\%; reported in 5 studies) ${ }^{136434972}$ in bullying following reporting.

In the 25 unique studies that described institutional facilitators of bullying, common facilitators were lack of enforcement (reported in 13 studies), 11620252836 43474950545665 the hierarchical structure of medicine (reported in 7 studies) 26545657636471 and normalisation of bullying (reported in 10 studies). ${ }^{3} 151923263134476265$ Individual-level data were not pooled as institutional facilitators of bullying were most commonly elicited via freeresponse portions of surveys with varying completion rates.

\section{Suggested strategies, interventions and outcomes}

Forty-nine unique studies suggested strategies to address academic bullying. These strategies included promoting anti-bullying policies (reported in 13 studies), ${ }^{314-163545} 53$ $\begin{array}{lllllll}54 & 56 & 58 & 59 & 66 & 71 & \text { education to prevent academic }\end{array}$ bullying (reported in 20 studies), ${ }^{1} \begin{array}{lllllllll}3 & 4 & 14 & 15 & 20 & 25 & 26 & 31\end{array}$ $33354548545963-657172$ establishing an anti-bullying oversight committee (reported in 10 studies), 21 22262830 3439586971 institutional support for victims (reported in 5 studies) ${ }^{3546586272}$ and internal reviews in which hospitals develop targeted solutions for their environment (reported in 5 studies) ${ }^{1522246063}$ (online supplemental table S3).

Of the 49 unique studies, 10 implemented organisationlevel interventions which included workshops with vignettes to improve recognition of bullying (reported in 4 studies) 23374244 ; a gender and power abuse committee that established reporting mechanisms and held mandatory workshops on mistreatment (reported in 1$)^{3}$; a gender equity office to handle reporting (reported in 1$)^{39}$; a professionalism-focused approach that included professionalism in employee contracts and performance reviews, and a professionalism office to handle student complaints $(\text { reported in } 1)^{26}$; zero-tolerance policies (reported in 1$)^{53}$ and institutional-level tracking of mistreatment to provide targeted staff education (reported in 2). ${ }^{21} 24$ All 10 studies had an uncontrolled before-after design, and as such, did not establish causality. In the studies of vignettes, common bullying behaviours were demonstrated to improve recognition of both subtle and overt acts of bullying. Of the 4 studies that involved bullying recognition workshops, 3 reported an associated improvement in bullying recognition. ${ }^{374244}$ In a study that developed a gender equity office, reporting was handled through an intermediary; decisions were binding with consequences for retaliation including termination of employment ${ }^{39}$ and $96 \%$ of all formal reports were resolved. In a study where a gender and power abuse committee was formed, there was an associated reduction in academic abuse. ${ }^{3}$ Similarly, in a study that used a multifaceted approach of developing a professionalism committee, and including professionalism in contracts and performance reviews, there was a $35.9 \%$ decrease in reporting of mistreatment and improved awareness of the reporting process. ${ }^{26}$ In a study where a clerkship committee monitored unprofessionalism, there was an associated reduction in narrative comments regarding unprofessionalism on end of rotation surveys. ${ }^{21}$ In a study assessing the impact of a professionalism retreat about mistreatment for consultants, there was no reduction in medical student mistreatment. ${ }^{13}$ In a study assessing the implementation of zero-tolerance policies, there was an associated improvement in awareness of bullying reporting processes. ${ }^{53}$

\section{Assessment of bias}

Twenty-eight studies had a low risk of bias, ${ }^{3481316-1922} 272930$ 3641454749-525556636671-7375 21 hadamoderateriskofbias ${ }^{1614152125283437}$ ${ }^{384043465458596167-70}$ and19hadahighriskofbias. ${ }^{2023242631-3335373942}$ 4448535760626465 Among the 58 survey studies, 14 sampled participants inappropriately, ${ }^{5} \quad 6 \quad 14 \quad 19 \quad 33 \quad 3540$ $4648545758606267 \quad 19$ had inadequate sample sizes or did not justify their sample size, ${ }^{1} 5 \quad 6 \quad 14 \quad 182531354046$

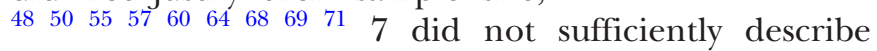
the participants, ${ }^{1} \quad 15 \quad 29 \quad 31 \quad 35 \quad 48 \quad 58 \quad 9$ had coverage bias, ${ }^{61440485457626465} 8 \mathrm{did}$ not have an appropriate statistical analysis ${ }^{1520283435646768}$ and30hadalowresponserate ${ }^{1514-162022283132}$ 34-3643 45 4749525657 59-62 65-67 697072 (online supplemental figure S2). Among the 10 before-after trials, 1 did not have prespecified inclusion criteria ${ }^{44} ; 5$ had low sample sizes or did not justify their sample size 2324374244 ; 3 did not have clearly defined, prespecified, consistently measured outcomes ${ }^{21} 24$ 44 9 did not blind participants $^{32324263739424453} ; 5$ did not account for loss to follow-up in their analysis ${ }^{2326424453}$ and 6 lacked statistical tests to assess for significant pre-intervention to post-intervention changes $^{242639424453}$ (online supplemental figure S3).

\section{DISCUSSION}

In this systematic review, we established a definition for academic bullying, identified common patterns of bullying and reported the impact on victims. We defined academic bullying as the abuse of authority by a perpetrator who targets the victim in order to impede their education or career through punishing behaviours that include overwork, destabilisation and isolation in an academic setting. Victims reported that academic bullying often resulted in stalled career advancement and thoughts of leaving the position. A majority of academic bullies were senior men, and a majority of victims were women. Barriers to reporting academic bullying included fear of reprisal, perceived hopelessness and institutional nonenforcement of anti-bullying policies. Strategies to overcome academic bullying, such as anti-bullying committees 


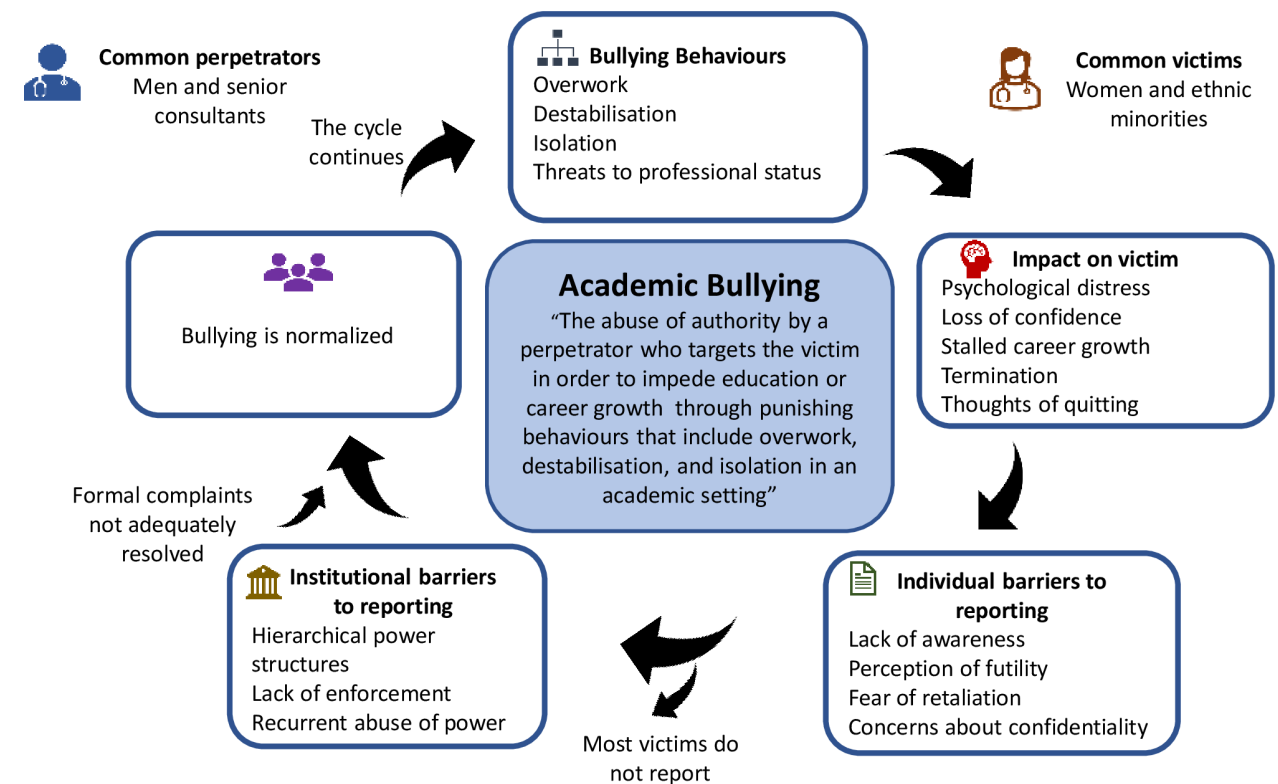

Figure 2 The definition, manifestations, impact, victims and perpetrators of academic bullying. Academic bullying is defined as an abuse of authority through punishing behaviours that include overwork, destabilisation and isolation. Victims are commonly women and ethnic minorities, while perpetrators are commonly men consultants. Individual and institutional factors contribute to the ongoing cycle of bullying.

and adding professionalism as a requirement for career advancement, were associated with an improvement in the prevalence of bullying and resolution of formal reports (figure 2). Our review differs from other systematic reviews of bullying in medicine in its scope and population studied. We included studies involving all medical and surgical disciplines, but limited our analysis to physicians and physician trainees. While prior reviews have focused on the prevalence of bullying ${ }^{76}$ or anti-bullying interventions, ${ }^{77}$ our comprehensive review expanded the focus to also include characteristics of bullies and victims, impact and outcomes of bullying, anti-bullying strategies and facilitators of academic bullying.

Several factors contribute to the prevalence of bullying within academia. The hierarchical structure lends itself to power imbalances and prevents victims from speaking out, especially when the aggressor is tenured. ${ }^{78}$ The relative isolation of departments within universities allows poor behaviour to go unchecked. Furthermore, the closed networks within departments lend themselves to mobbing behaviour and cause victims to fear of being blacklisted for speaking out. ${ }^{79}$

A lack of clarity around the definition can limit awareness and reporting. ${ }^{50}$ The Graduation Questionnaire administered to all American medical students found that in years where respondents were asked if they had been bullied, the estimated prevalence was lower than when they were asked about specific bullying behaviours. ${ }^{15}$ Surveys on bullying should include a list of defining behaviours to increase clarity and accuracy in responses. ${ }^{80}$ Even in institutions with established reporting systems, respondents were often unaware of how to file a report. ${ }^{47}$ We found that victims of academic bullying rarely filed reports, primarily due to fear of retaliation. Reporting was not consistently effective and was more likely to worsen bullying.

We found that consultants were the most common perpetrators of bullying at all levels of training. Residents often bullied medical students. No studies assessed the relative contribution of fellows and senior residents to resident bullying. Among studies that analysed bullying among consultants by seniority, senior consultants were a commonly reported source of bullying. ${ }^{6} 8404373$ Women and ethnic minorities reported higher rates of bullying among demographic groups surveyed, although race and ethnicity were infrequently assessed in the surveys included in this study. While some argue that the increasing proportion of women trainees ${ }^{81} 82$ may change dynamics in healthcare settings, the leaky academic pipeline in which women remain under-represented in several academic specialties and in positions of leadership makes them vulnerable to the power asymmetries in academic medicine. $^{83}$

Our review illustrates the self-reported harms of academic bullying. Victims experienced depressive symptoms, self-perceived loss of clinical ability and termination of employment. Academic bullying has been linked to depression, ${ }^{51}$ substance abuse, ${ }^{84}$ and hospitalisation for coronary artery or cerebrovascular disease ${ }^{85}$ Bullying costs the NHS of the UK $£ 325$ million annually due to reduced performance and increased staff turnover. ${ }^{86}$ Disruptive behaviour, linked to bullying in the perioperative setting, has been linked to $27 \%$ of patient deaths, $67 \%$ of adverse events and $71 \%$ of medical errors. ${ }^{7}$ Reasons for consultant error include intimidation leading to a fear of communicating sources of harm and slow response times. ${ }^{87} \mathrm{We}$ found that academic bullying negatively impacted patient safety. In a study of emergency medicine residents, $90 \%$ 
reported examples in which disruptive behaviour affected patient care, and $51 \%$ were less likely to call an abusive consultant. $^{18}$

Interventions reported as effective were organisation level. Anti-bullying committees involving staff and learners can research bullying within their institution and address the most common disruptive behaviours through targeted interventions. ${ }^{67}$ An organisation-level, rather than individual-level approach, may address the root causes of academic bullying as well as the organisational culture that facilitates ongoing bullying. We found that anti-bullying committees typically included three elements: (1) a multidisciplinary team that includes clinicians and other front-line staff; (2) development of anti-bullying policies and a reporting process; and (3) an education campaign to promote awareness of policies. Owing to their multifaceted nature, it is challenging to evaluate the relative contributions of their components. Without well-designed trials, the effects of anti-bullying interventions are unknown. All of the intervention studies used before-after designs, which did not account for confounding variables, co-interventions, and background changes in policy or practice; the majority were at high risk of bias. Furthermore, among studies that implemented anti-bullying workshops, the majority interviewed participants immediately after the workshop without longitudinal follow-up to determine if benefits were sustained.

The need for a confidential reporting process was raised in the studies included in this review, but few described how confidentiality could be maintained when the report has to describe details of the bullying that may be only privy to the perpetrator and victim. The reporting process could take the form of the Office of Gender Equity at the University of California, where the accuser and the accused do not meet face to face; the discipline process is through an intermediary. ${ }^{39} \mathrm{~A}$ unique, non-punitive approach is the restorative justice approach used at Dalhousie University where victims, offenders, and administrators work collaboratively to address sexual harassment and reintegrate offenders. ${ }^{88}$ Reporting may have been ineffective in this review due to the impunity offered to prominent consultants. Senior personnel, particularly those who are well-known and successful in grant funding, are often considered 'untouchable', beyond reproach by their institutions. ${ }^{89}$ Behaviour is often learnt and modelling positive behaviours may break the cycle of bullying in medicine. ${ }^{90}$ One approach would be making professionalism a requirement for promotion and career advancement, as in the Department of Medicine at the University of Toronto in Canada ${ }^{91}$ or the University of Colorado School of Medicine. ${ }^{26}$

\section{Strengths and limitations}

The strengths of this review include its broad scope, capturing several aspects of academic bullying, and its size ( $\mathrm{n}=68$ studies, 82349 consultants and trainees). The cohort included was diverse, comprising several specialties and countries. We explicitly defined eligibility criteria and extracted data in duplicate. We used established tools to assess the risk of bias.

There are several limitations that should be acknowledged. There is no validated definition of academic bullying, and the included studies varied in their description of bullying. Most studies used questionnaires that were not previously validated. The survey instruments across studies differed from each other, and their results had to be pooled according to themes. We could not account for differences in institutional culture and hospital systems in the responses of survey participants. Estimates of the prevalence of bullying must be interpreted in light of the self-reported nature of bullying surveys. Data on bully/victim demographics were underrepresented. Selection bias was a significant concern: 14 studies used convenience sampling, and 2 included voluntary focus groups for victims of bullying. Overall, the response rate was $59.2 \%$, with a range of $12 \%-100 \%$. Surrogate outcomes such as awareness of bullying were used, and the reporting of outcomes was inconsistent. As such, the effect of anti-bullying interventions must be interpreted cautiously.

\section{FUTURE DIRECTIONS}

Significant gaps exist in the quality of the academic bullying literature, particularly with inconsistent definitions and limitations in study methodology. Our definition may be used to provide the breadth and granularity required to sufficiently capture cases of academic bullying in medicine. Studies on the impact of academic bullying would benefit from standardised, validated survey instruments. Although randomisation and blinding are not always possible to test the effect of interventions, a control group should be included in anti-bullying intervention studies.

\section{CONCLUSIONS}

Academic bullying refers to specific behaviours that disrupt the learning or career of the intended target and commonly consists of exclusion and overwork. The consequences include significant psychiatric distress and loss of career opportunities. Bullies tend to be men and senior consultants, whereas victims tend to be women. The fear of reprisal and non-enforcement of anti-bullying policies are the greatest barriers to addressing academic bullying. Results of bullying interventions must be interpreted with caution due to their methodological quality and reliance on surrogate measures. There is a need for well-designed trials with transparent reporting of relevant outcomes and accounting for temporal trends.

Contributors TA contributed to study design, informed the search strategy, extracted and synthesised study data, and drafted and edited the manuscript. YE informed the search strategy, extracted and synthesised study data, and edited the manuscript. HGCVS conceived the study idea, informed the search strategy, analysed the data, drafted and edited the manuscript, and supervised the conduct 
of the study. HGCVS affirms that the manuscript is an honest, accurate and transparent account of the study being reported; that no important aspects of the study have been omitted; and that any discrepancies from the study as planned have been explained.

Funding HGCVS receives support from the Canadian Institutes of Health Research, the Heart and Stroke Foundation, the Women As One Escalator Award and McMaster Department of Medicine.

Competing interests None declared.

Patient consent for publication Not required.

Provenance and peer review Not commissioned; externally peer reviewed.

Data availability statement All data relevant to the study are included in the article or uploaded as supplemental information.

Supplemental material This content has been supplied by the author(s). It has not been vetted by BMJ Publishing Group Limited (BMJ) and may not have been peer-reviewed. Any opinions or recommendations discussed are solely those of the author(s) and are not endorsed by BMJ. BMJ disclaims all liability and responsibility arising from any reliance placed on the content. Where the content includes any translated material, BMJ does not warrant the accuracy and reliability of the translations (including but not limited to local regulations, clinical guidelines, terminology, drug names and drug dosages), and is not responsible for any error and/or omissions arising from translation and adaptation or otherwise.

Open access This is an open access article distributed in accordance with the Creative Commons Attribution Non Commercial (CC BY-NC 4.0) license, which permits others to distribute, remix, adapt, build upon this work non-commercially, and license their derivative works on different terms, provided the original work is properly cited, appropriate credit is given, any changes made indicated, and the use is non-commercial. See: http://creativecommons.org/licenses/by-nc/4.0/.

ORCID iD

Tauben Averbuch http://orcid.org/0000-0001-9383-9312

\section{REFERENCES}

1 Scott J, Blanshard C, Child S. Workplace bullying of junior doctors: cross-sectional questionnaire survey. N Z Med J 2008;121:10-14

2 Lewis D. Workplace bullying. Body Qual Res 2019;42:91-106.

3 Fried JM, Vermillion M, Parker NH, et al. Eradicating medical student mistreatment: a longitudinal study of one institution's efforts. Acad Med 2012;87:1191-8

4 Oku AO, Owoaje ET, Oku OO, et al. Mistreatment among undergraduate medical trainees: a case study of a Nigerian medical school. Niger J Clin Pract 2014;17:678-82.

5 Kulaylat AN, Qin D, Sun SX, et al. Perceptions of mistreatment among trainees vary at different stages of clinical training. BMC Med Educ 2017;17:1-6.

6 Malinauskiene V, Bernotaite L, Leisyte P. Bullying behavior and mental health. Med Pr 2017;68:307-14.

7 Lavelle-Jones M. Bullying and Undermining Campaign - Let's Remove it, 2017The Royal College of Surgeons of Edinburgh. Available: https://www.rcsed.ac.uk/news-public-affairs/news/2017/ june/bullying-and-undermining-campaign-let-s-remove-it [Accessed 03 Mar 2019].

8 Quine L. Workplace bullying in NHS community trust: staff questionnaire survey. BMJ 1999;318:228-32.

9 Okechukwu CA, Souza K, Davis KD, et al. Discrimination, harassment, abuse, and bullying in the workplace: contribution of workplace injustice to occupational health disparities. Am J Ind Med 2014:57:573-86.

10 McKay R, Arnold DH, Fratzl J, et al. Workplace bullying in academia: a Canadian study. Employ Respons Rights J 2008;20:77-100.

11 National Heart, Lung, and Blood Institute. Quality assessment tool for before-after (pre-post) studies with no control group. Available: https://www.nhlbi.nih.gov/health-topics/study-quality-assessmenttools

12 Joanna Briggs Institute. Checklist for prevalence studies. Available: http://joannabriggs.org/research/critical-appraisal-tools.html

13 Oser TK, Haidet P, Lewis PR, et al. Frequency and negative impact of medical student mistreatment based on specialty choice: a longitudinal study. Acad Med 2014;89:755-61.

14 Chadaga AR, Villines D, Krikorian A. Bullying in the American graduate medical education system: a national cross-sectional survey. PLoS One 2016;11:e0150246.
15 Mavis B, Sousa A, Lipscomb W, et al. Learning about medical student mistreatment from responses to the medical school graduation questionnaire. Acad Med 2014;89:705-11.

16 Stasenko M, Tarney C, Seier K, et al. Sexual harassment and gender discrimination in gynecologic oncology. Gynecol Oncol 2020;159:317-21.

17 Kemper KJ, Schwartz A, Pediatric Resident Burnout-Resilience Study Consortium. Bullying, discrimination, sexual harassment, and physical violence: common and associated with burnout in pediatric residents. Acad Pediatr 2020;20:991-7.

18 Huber M, Lopez J, Messman A, et al. Emergency medicine resident perception of abuse by consultants: results of a national survey. Ann Emerg Med 2020;76:814-5.

19 Raj A, Freund KM, McDonald JM, et al. Effects of sexual harassment on advancement of women in academic medicine: a multi-institutional longitudinal study. EClinicalMedicine 2020;20:100298.

20 D'Agostino JP, Vakharia KT, Bawa S, et al. Intimidation and sexual harassment during plastic surgery training in the United States. Plast Reconstr Surg Glob Open 2019;7:e2493.

21 Kappy MD, Holman E, Kempner S, et al. Identifying medical student mistreatment in the obstetrics and gynecology clerkship. J Surg Educ 2019;76:1516-25.

22 Hammoud MM, Appelbaum NP, Wallach PM, et al. Incidence of resident mistreatment in the learning environment across three institutions. Med Teach 2021;43:334-40.

23 Castillo-Angeles M, Calvillo-Ortiz R, Acosta D, et al. Mistreatment and the learning environment: a mixed methods approach to assess knowledge and raise awareness amongst residents. J Surg Educ 2019;76:305-14.

24 House JB, Griffith MC, Kappy MD, et al. Tracking student mistreatment data to improve the emergency medicine clerkship learning environment. West J Emerg Med 2018;19:18-22 https:// escholarship.org/uc/item/9md5263b

25 Zurayk LF, Cheng KL, Zemplenyi M, et al. Perceptions of sexual harassment in oral and maxillofacial surgery training and practice. $J$ Oral Maxillofac Surg 2019;77:2377-85.

26 Lind KT, Osborne CM, Badesch B, et al. Ending student mistreatment: early successes and continuing challenges. Med Educ Online 2020;25:1690846.

$27 \mathrm{Hu}$ Y-Y, Ellis RJ, Hewitt DB, et al. Discrimination, abuse, harassment, and burnout in surgical residency training. $N$ Engl $J$ Med 2019;381:1741-52.

28 Balch Samora J, Van Heest A, Weber K, et al. Harassment, discrimination, and bullying in orthopaedics: a work environment and culture survey. J Am Acad Orthop Surg 2020;28:e1097-104.

29 Zhang LM, Ellis RJ, Ma M, Prevalence MM, et al. Prevalence, types, and sources of bullying reported by US general surgery residents in 2019. JAMA 2020;323:2093-5.

30 Ayyala MS, Rios R, Wright SM. Perceived bullying among internal medicine residents. JAMA 2019;322:576-8.

31 Chowdhury ML, Husainat MM, Suson KD. Workplace bullying of urology residents: implications for the patient and provider. Urology 2019;127:30-5.

32 Wolfman DJ, Parikh JR. Resident bullying in diagnostic radiology. Clin Imaging 2019;55:47-52.

33 Chung MP, Thang CK, Vermillion M, et al. Exploring medical students' barriers to reporting mistreatment during clerkships: a qualitative study. Med Educ Online 2018;23:1478170.

34 Kemp MT, Smith M, Kizy S, et al. Reported mistreatment during the surgery clerkship varies by student career choice. J Surg Educ 2018:75:918-23.

35 Wear D, Aultman J. Sexual harassment in academic medicine: persistence, Non-Reporting, and institutional response. Med Educ Online 2005;10:4377-11.

36 Rouse LP, Gallagher-Garza S, Gebhard RE, et al. Workplace bullying among family physicians: a gender focused study. J Womens Health 2016;25:882-8.

37 Kulaylat AN, Qin D, Sun SX, et al. Aligning perceptions of mistreatment among incoming medical trainees. J Surg Res 2017;208:151-7.

38 Jagsi R, Griffith $\mathrm{KA}$, Jones $\mathrm{R}$, et al. Sexual harassment and discrimination experiences of academic medical faculty. JAMA 2016;315:2120-1.

39 Best CL, Smith DW, Raymond JR, et al. Preventing and responding to complaints of sexual harassment in an academic health center: a 10 -year review from the medical University of South Carolina. Acad Med 2010;85:721-7.

40 Shrier DK, Zucker AN, Mercurio AE, et al. Generation to generation: discrimination and harassment experiences of physician mothers and their physician daughters. $J$ Womens Health 2007;16:883-94. 
41 Carr PL, Ash AS, Friedman $\mathrm{RH}$, et al. Faculty perceptions of gender discrimination and sexual harassment in academic medicine. Ann Intern Med 2000;132:889-96.

42 Benmore G, Henderson S, Mountfield J, et al. The Stopit! programme to reduce bullying and undermining behaviour in hospitals. $J$ Health Organ Manag 2018;32:428-43.

43 Shabazz T, Parry-Smith W, Oates S, et al. Consultants as victims of bullying and undermining: a survey of Royal College of obstetricians and gynaecologists consultant experiences. BMJ Open 2016;6:e011462.

44 Cresswell K, Sivashanmugarajan V, Lodhi W, et al. Bullying workshops for obstetric trainees: a way forward. Clin Teach 2015;12:83-7.

45 Cheema S, Ahmad K, Giri SK, et al. Bullying of junior doctors prevails in Irish health system: a bitter reality. Ir Med J 2005;98:12-14.

46 Duru P, Ocaktan ME, Çelen Ümit, et al. The effect of workplace bullying perception on psychological symptoms: a structural equation approach. Saf Health Work 2018;9:210-5.

47 Chambers CNL, Frampton CMA, McKee M, et al. 'It feels like being trapped in an abusive relationship': bullying prevalence and consequences in the New Zealand senior medical workforce: a cross-sectional study. BMJ Open 2018;8:e020158.

48 Al-Shafaee M, Al-Kaabi Y, Al-Farsi Y, et al. Pilot study on the prevalence of abuse and mistreatment during clinical internship: a cross-sectional study among first year residents in Oman. BMJ Open 2013;3:1-7.

49 Ling M, Young CJ, Shepherd HL, et al. Workplace bullying in surgery. World J Surg 2016;40:2560-6.

50 Ahmadipour $\mathrm{H}$, Vafadar R. Why mistreatment of medical students is not reported in clinical settings: perspectives of trainees. Indian $J$ Med Ethics 2016;1:215-8.

51 Loerbroks A, Weigl M, Li J, et al. Workplace bullying and depressive symptoms: a prospective study among junior physicians in Germany. J Psychosom Res 2015;78:168-72.

52 Owoaje ET, Uchendu OC, Ige OK. Experiences of mistreatment among medical students in a university in South West Nigeria. Niger J Clin Pract 2012;15:214-9.

53 Meloni M, Austin M. Implementation and outcomes of a zero tolerance of bullying and harassment program. Aust Health Rev 2011;35:92-4.

54 Imran N, Jawaid M, Haider II, et al. Bullying of junior doctors in Pakistan: a cross-sectional survey. Singapore Med J 2010;51:592-5.

55 Ogunsemi OO, Alebiosu OC, Shorunmu OT. A survey of perceived stress, intimidation, harassment and well-being of resident doctors in a Nigerian teaching hospital. Niger J Clin Pract 2010;13:183-6.

56 Nagata-Kobayashi S, Maeno T, Yoshizu M, et al. Universal problems during residency: abuse and harassment. Med Educ 2009;43:628-36.

57 Rautio A, Sunnari V, Nuutinen M, et al. Mistreatment of university students most common during medical studies. BMC Med Educ 2005;5:1-12.

58 Kapoor S, Ajinkya S, Jadhav PR. Bullying and Victimization Trends in Undergraduate Medical Students - A Self-Reported Cross-Sectional Observational Survey. J Clin Diagn Res 2016;10:VC05-8.

59 Peres MFT, Babler F, Arakaki JNL, et al. Mistreatment in an academic setting and medical students' perceptions about their course in São Paulo, Brazil: a cross-sectional study. Sao Paulo Med J 2016;134:130-7.

60 Gan R, Snell L. When the learning environment is suboptimal: exploring medical students' perceptions of "mistreatment". Acad Med 2014:89:608-17.

61 Dikmetaș E, Top M, Ergin G. An examination of mobbing and burnout of residents. Turk Psikiyatri Derg 2011;22:137-49.

62 Llewellyn A, Karageorge A, Nash L. Bullying and sexual harassment of junior doctors in New South Wales, Australia: rate and reporting outcomes. Aust Heal Rev 2018.

63 Elghazally NM, Atallah AO. Bullying among undergraduate medical students at Tanta University, Egypt: a cross-sectional study. Libyan J Med 2020;15:1816045.

64 Colenbrander L, Causer L, Haire B. 'If you can't make it, you're not tough enough to do medicine': a qualitative study of Sydney-based medical students' experiences of bullying and harassment in clinical settings. BMC Med Educ 2020;20:1-12.
65 Brown A, Bonneville G, Glaze S, Nevertheless GS. Nevertheless, they persisted: how women experience gender-based discrimination during postgraduate surgical training. J Surg Educ 2021;78:17-34.

66 Askew DA, Schluter PJ, Dick M-L, et al. Bullying in the Australian medical workforce: cross-sectional data from an Australian e-Cohort study. Aust Health Rev 2012;36:197-204.

67 Eriksen GS, Nygreen I, Rudmin FW. Bullying among hospital staff: use of psychometric triage to identify intervention priorities. $E$ Journal of Applied Psychology 2011;7:26-31.

68 labal A, Khattak A, Malik FR. Bullying behaviour in operating theatres. J Ayub Med Coll Abbottabad 2020;32:352-355.

69 Brown J, Drury L, Raub K, et al. Workplace harassment and discrimination in gynecology: results of the AAGL member survey. $J$ Minim Invasive Gynecol 2019;26:838-46.

70 Chrysafi P, Simou E, Makris M, et al. Bullying and sexual discrimination in the Greek health care system. J Surg Educ 2017;74:690-7

71 Gadit AAM, Mugford G. A pilot study of bullying and harassment among medical professionals in Pakistan, focussing on psychiatry: need for a medical Ombudsman. J Med Ethics 2008;34:463-6.

72 Crebbin W, Campbell G, Hillis DA, et al. Prevalence of bullying, discrimination and sexual harassment in surgery in Australasia. ANZ J Surg 2015;85:905-9.

73 Malinauskiene V, Bernotaite L. 0392 Workplace bullying and posttraumatic stress symptoms among family physicians in Lithuania. Occup Environ Med 2014;71:A113.2-A113.

74 Aaronson KD, Cowger J. Heart failure prognostic models: why bother? Circ Heart Fail 2012;5:6-9.

75 Afkhamzadeh A, Mohamadi Bolbanabad A, Moloudi B, et al. Workplace violence against physicians and medical students in West part of Iran. Int J Hum Rights Healthc 2019;12:116-23.

76 Fnais $\mathrm{N}$, Soobiah $\mathrm{C}$, Chen $\mathrm{MH}$, et al. Harassment and discrimination in medical training: a systematic review and meta-analysis. Acad Med 2014;89:817-27.

77 Gamble Blakey A, Smith-Han K, Anderson L, et al. Interventions addressing student bullying in the clinical workplace: a narrative review. BMC Med Educ 2019;19:1-13.

78 Sharma M. Workplace bullying: an exploratory study in Australian academia. Grants Regist 2019:315-6.

79 Khoo S. Academic mobbing: hidden health hazard at workplace. Malays Fam Physician 2010;5:61-7.

80 General Medical Council. National training survey 2014, 2014.

81 Association of American medical colleges (AAMC). The majority of U.S. medical students are women; 2019

82 Jefferson L, Bloor K, Maynard A. Women in medicine: historica perspectives and recent trends. Br Med Bull 2015;114:5-15.

83 Whitelaw S, Kalra A, Van Spall HGC. Flattening the hierarchies in academic medicine: the importance of diversity in leadership, contribution, and thought. Eur Heart J 2020;41:9-10.

84 Niedhammer I, David S, Degioanni S, et al. Workplace bullying and psychotropic drug use: the mediating role of physical and mental health status. Ann Occup Hyg 2011;55:152-63.

$85 \mathrm{Xu}$ T, Magnusson Hanson LL, Lange T. Workplace bullying and workplace violence as risk factors for cardiovascular disease: a multi-cohort study. Eur Heart J 2018;0:1-12.

86 Mistry M, Latoo J. Bullying : a growing workplace menace. Br J Med Pract 2009;2:23-6.

87 Rosenstein $\mathrm{AH}$. Physician disruptive behaviors: five year progress report. World J Clin Cases 2015;3:930.

88 Acosta D, Karp DR. Restorative justice as the Rx for mistreatment in academic medicine: applications to consider for learners, faculty, and staff. Acad Med 2018;93:354-6.

89 Watters DA, Hillis DJ. Discrimination, bullying and sexual harassment: where next for medical leadership? Med J Aust 2015;203:175.

90 Lehmann LS, Sulmasy LS, Desai S, et al. Hidden curricula, ethics, and professionalism: optimizing clinical learning environments in becoming and being a physician: a position paper of the American College of physicians. Ann Intern Med 2018;168:506-8.

91 Singer $\mathrm{H}$. Addressing Unprofessional behaviour among physicians, 2018St. Michael's Hospital. Available: http://stmichaelshospital.com/ media/detail.php?source=hospital_news/2018/0730 [Accessed 02 Mar 2019]. 